\title{
Birth Characteristics and Risk of Lymphoma in Young Children
}

\author{
Erin L Marcotte ${ }^{1}$, Beate Ritz ${ }^{1}$, Myles Cockburn², Christina A Clarke ${ }^{3}$, and Julia E Heck1 \\ ${ }^{1}$ Department of Epidemiology, Fielding School of Public Health, University of California, Los \\ Angeles, Box 951772, 650 Charles E Young Drive, Los Angeles, CA, 90095-1772 USA \\ ${ }^{2}$ Department of Preventive Medicine, Keck School of Medicine, University of Southern California, \\ 1441 Eastlake Ave MC 9175, Los Angeles, CA 90089-9175 USA \\ ${ }^{3}$ Cancer Prevention Institute of California, 2201 Walnut Ave Suite 300, Fremont, CA, 94538-2334 \\ USA
}

\section{Abstract}

Background-Lymphoma is the third most common childhood malignancy and comprises two types, Hodgkin lymphoma (HL) and non-Hodgkin lymphoma (NHL). The etiology of pediatric lymphomas is largely unknown, but has been suggested to have prenatal origins.

Methods-In this population-based study, California birth certificates were identified for 478 lymphoma cases diagnosed in children 0-5 years of age between 1988-2007; 208,015 controls frequency-matched by birth year were randomly selected from California birth records.

Results-Compared to non-Hispanic whites, Hispanic children had an increased risk of HL (odds ratio (OR) and 95\% confidence interval (CI) 2.43 [1.14, 5.17]), and in particular, were diagnosed more often with the mixed cellularity subtype. For all types of lymphoma, we observed an about two-fold risk increase with indicators for high risk pregnancies including tocolysis, fetopelvic disproportion and previous preterm birth. NHL risk doubled with the complication premature rupture of membranes (OR and 95\% CI $2.18[1.12,4.25]$ ) and HL with meconium staining of amniotic fluids (OR and 95\% CI 2.55 [1.01, 6.43]).

Conclusion-These data support previously reported associations between Hispanic ethnicity and $\mathrm{HL}$ and suggest that pregnancy related factors, such as intra-uterine infections and factors associated with preterm labor, may be involved in lymphoma pathogenesis.

\section{MeSH Keywords}

Children; Epidemiology; Hispanics; Hodgkin Lymphoma; Lymphoma, Non-Hodgkin; Pregnancy

\footnotetext{
(c) 2013 Elsevier Inc. All rights reserved.

Corresponding author: Julia Heck, Department of Epidemiology, Box 951772, 650 Charles E. Young Drive, Los Angeles, CA 90095-1772, (Tel) 1310825 8579, (Fax) 1310206 6039, jeheck@ucla.edu.

Conflicts of Interest: The authors report no conflicts of interest.

Publisher's Disclaimer: This is a PDF file of an unedited manuscript that has been accepted for publication. As a service to our customers we are providing this early version of the manuscript. The manuscript will undergo copyediting, typesetting, and review of the resulting proof before it is published in its final citable form. Please note that during the production process errors may be discovered which could affect the content, and all legal disclaimers that apply to the journal pertain.
} 


\section{Introduction}

Lymphoma is the third most common childhood malignancy, accounting for approximately $15 \%$ of cancers diagnosed in children (0-14 years of age). (1) Pediatric lymphoma is relatively rare, with an incidence rate of 16.5 per million in the US. (2) Thus, pediatric lymphomas are difficult to study epidemiologically and their etiologies remain largely unknown. There is a growing body of evidence that exposures during the prenatal period, which is a highly vulnerable period of development $(3,4)$, may contribute to development of pediatric lymphoma. $(5,6)$

Pediatric lymphoma comprises two main types: Hodgkin lymphoma (HL) and nonHodgkin's lymphomas (NHL). HL is rare among young children ages 0-10 and occurs more frequently among adolescents. NHL is the most common form of lymphoma diagnosed among 0-5 year olds. Nearly all lymphoma diagnoses among infants younger than 1 year of age are miscellaneous lymphoreticular neoplasms. (2)

HL typically arises from B lymphocytes with characteristic Reed-Sternberg cells, which are large, clonal, multinucleated, and sometimes contain Epstein-Barr virus (EBV) genomic sequences (7). EBV is found in approximately $40-50 \%$ of all HL cases in developed countries and up to $80 \%$ in developing countries, most commonly among cases diagnosed $0-10$ years of age $(8,9)$.

NHL includes lymphoblastic lymphoma, Burkitt lymphoma, and large cell lymphoma. (10) Immunodeficiency, including immunosuppressive therapy, congenital immunodeficiency syndromes, and HIV/AIDS all predispose to NHL. $(11,12)$

There are few studies reporting on pregnancy exposures or birth certificate variables and pediatric lymphoma.(13-21) We hypothesized that cancers in the earliest period of life (0-5 years of age) are most likely to have origins in the prenatal period. Here we present results from a large California population-based case-control study of pediatric lymphoma that employed birth records to examine pregnancy-related risk factors.

\section{Materials and Methods}

\section{Subjects}

The study utilized two sources of population-based data in California: birth certificate and California Cancer Registry. Using the cancer registry, we identified all lymphoma cases diagnosed in California children 0-5 years of age between 1988-2007. Lymphoma cases were defined using International Classification of Childhood Cancer, Third edition (ICCC-3) (22) classification, codes 021 (Hodgkin lymphomas), 022 (Non-Hodgkin lymphomas, except Burkitt lymphoma), 023 (Burkitt lymphoma), 024 (miscellaneous lymphoreticular neoplasms), or 025 (unspecified lymphomas). Lymphoma cases were part of a case-control study of all childhood cancers ages 0-5 in California during this period, in which we successfully matched $89 \%$ of all cases to their California birth certificate (birth years 1986-2007), resulting in a total case population of 10,485.(23) From CA birth certificate files, we randomly selected twenty controls per case, frequency matched on birth year, 
resulting in 209,700 controls. We removed cancer cases from the birth records before frequency matching, to arrive at a set of eligible controls who had not been diagnosed with cancer in California. We cross-checked CA death records and excluded controls who died before age six $(\mathrm{n}=1,522)$. We also excluded likely non-viable births, defined as birth weight of $<500$ grams ( $n=27$ controls, $n=0$ cases) or birth before 20 weeks of gestation ( $n=136$ controls, $n=0$ cases). The final dataset included 478 lymphoma cases and 208,015 controls.

California birth certificates provided demographic, reproductive history, and gestational information. Gestational variables included complications of pregnancy and labor/delivery, including abnormal conditions and clinical procedures related to the newborn, and month of prenatal care initiation. Because some birth certificate variables, specifically those related to pregnancy and labor/delivery complications, were not collected each year, we included information in Table 4 which indicates the set of study years that each variable is available.

As our study used de-identified records, we were not required to obtain informed consent from study subjects. Use of human subject data was approved by the UCLA Institutional Review Board, California Health and Human Services Agency Committee for the Protection of Human Subjects, and California Cancer Registry.

\section{Statistical Methods}

We used unconditional multivariate logistic regression to calculate odds ratios (OR) and 95\% confidence intervals (CI) while controlling for the matching factor.

Infants were considered preterm if born at $<37$ weeks and post-term at $>42$ weeks of gestation.(24) Low birth weight (LBW) and high birth weight (HBW) were defined as birth weights $<2500$ grams and $\geq 4000$ grams, respectively.(24) All pregnancy and labor/delivery complications were recorded as dichotomous (yes/no) variables. We created a sex- and raceadjusted size for gestational age variable using the method described by Alexander et al (25). This variable is based on $10^{\text {th }}$ and $90^{\text {th }}$ percentile sex-specific birth weight values for each gestational week between 20 to 45 weeks for maternal race/ethnicity group (nonHispanic white, Hispanic of any race, African American, Asian/Pacific Islander, and other). In order to generate the percentile values, we included singleton live births in California born between 1988 and 2006 with gestational ages between weeks 20 and 45 and birth weight within the range provided by Alexander et al, $1996(\mathrm{n}=10,134,074)$. These values included separate percentiles for males and females by gestational week for each race/ethnic group. For each sex and race group, we defined small for gestational age as any birth weight below the $10^{\text {th }}$ percentile, and large for gestational age as any birth weight above the $90^{\text {th }}$ percentile.

Other variables included in multivariate regression included maternal age (continuous), race/ ethnicity (non-Hispanic White, Hispanic of any race, other), and primary payment source for prenatal care. We used payment source for prenatal care as a proxy for socioeconomic status, as we have previously found it to be associated with income (26), and categorized this variable as private insurance (including Health Maintenance Organizations (HMO), Blue Cross-Blue Shield, and any other private insurance), and other payment methods (including government aid programs, worker's compensation, Title V, CHAMPUS/ 
TRICARE, and self-pay). We adjusted all effect estimates for birth year. We considered only those exposures with at least five affected cases, as well as risk factors reported in other studies.

We stratified by lymphoma type, separating HL, NHL (including Burkitt lymphoma and other NHL), and miscellaneous and unspecified lymphomas. Due to the rarity of some pregnancy complications, we adjusted stratified analyses only for birth year. In additional sensitivity analyses, we assessed the impact of US- versus foreign-born status among Hispanics on analysis of infant birth weight and size for gestational age. Finally, we examined the distribution of histological subtypes of HL by race/ethnicity to examine the prevalence of the mixed cellularity subtype since previous studies have suggested that this subtype is associated with EBV-related HL.

\section{Results}

Lymphoma cases were more often male and of high birth weight (HBW) than controls (Tables 1 and 2). When considering all lymphoma cases combined, mothers of cases more frequently reported lower education levels than control mothers and were more likely to report either no prenatal care or prenatal care only after the first trimester.

In multivariate analyses, we observed a strong positive association between maternal Hispanic ethnicity and HL (OR and 95\% CI: $2.43[1.14,5.17])$ and a negative association between maternal Hispanic ethnicity and NHL (OR and 95\% CI: $0.80[0.58,1.10]$ ) (Table 3). We observed similar associations when both parents reported Hispanic ethnicity (ORs and 95\% CIs: 2.23 [0.99, 5.01] for HL and 0.81 [0.57, 1.15] for NHL). Among birth complications and other indicators for high risk pregnancies, tocolysis, previous preterm birth, and fetopelvic disproportion conferred an approximately 2 -fold increase in risk of any type of lymphoma (Table 4). For maternal febrile status, prolonged labor, premature rupture of membranes, moderate to heavy meconium staining of the amniotic fluid, large size for gestational age, $\mathrm{HBW}$, and previous stillbirth our data suggested positive associations with lymphoma although confidence intervals included the null value. Conversely, for preeclampsia, induction of labor, and breech or other abnormal presentation our data suggested negative associations, with confidence intervals again including the null. Including birth weight in the multivariate model for associations between lymphoma and pregnancy and labor complications and, separately, including child's sex in the multivariate model for birth weight did not change our estimates more than minimally ( $<10 \%$ change), (results not shown).

In analyses stratified by lymphoma type, we observed positive associations between HL and meconium staining (OR and 95\% CI: 2.55 [1.01, 6.43]), and between NHL and premature rupture of the membranes (OR and 95\% CI: 2.18 [1.12, 4.25]) (Table 5). Positive associations were also observed between HBW and miscellaneous and unspecified lymphomas (OR and 95\% CI: 1.68 [1.09, 2.61]).

Foreign-born status among Hispanics conferred a slight decrease in odds of any lymphoma compared to US-born Hispanics, although confidence intervals included the null value (OR 
$0.8195 \%$ CI $0.58,1.12$ ), and this result is similar to our estimate for foreign-born mothers of any race. When we examined birth weight and size for gestational age among Hispanics stratified by maternal birthplace, we did not observe differences between cases and controls, although among cases, Hispanic mothers born in the US gave birth to more low birth weight infants than foreign-born Hispanic mothers (results not shown).

A higher proportion of Hispanic than white HL cases was diagnosed with the mixed cellularity subtype ( $27.9 \%$ and $7.7 \%$, respectively). The nodular lymphocyte-predominant subtype was more common among whites than Hispanics (4.7\% and 30.8\% for Hispanics and whites, respectively) (Supplemental Table 1).

Although we observed fewer than five affected cases for polyhydramnios and anemia, these factors were associated with lymphoma in a previous study (27), thus we report our observed frequencies of these factors here. Four case mothers and 1617 control mothers suffered from anemia, while one case and 986 control mothers suffered from polyhydramnios/oligohydramnios.

\section{Discussion}

We investigated associations between pregnancy-related factors and pediatric lymphomas in a large, population-based series of children age 0-5 in California. For NHL, we observed an increase in risk for male sex and a risk reduction for Hispanic ethnicity, foreign-born status, and non-private health insurance, an indicator of low SES. Male sex, lower paternal education, and Hispanic ethnicity were related to a risk increase for HL. NHL risk was increased for infants born after premature rupture of the membranes, a marker of intrauterine infection, while HL risk was higher among infants born with meconium staining of the amniotic fluid, a marker of fetal distress. Generally these estimates were imprecise and had wide confidence intervals due to small sample size, although the association between $\mathrm{HL}$ and meconium staining was statistically significant.

The associations we observed between Hispanic ethnicity and both HL and NHL are consistent with reports from a recent study that pooled data across the US (28) and the 2000-2008 SEER data(29)(29)(29)(32)(31)(30)(29)(28)(27)(26)(25)(24)(23)(22)(21)(20, 21). The increased risk of HL among Hispanics may be attributable to Epstein - Barr virus (EBV). Several studies among both pediatric and adult HL cases have reported that Hispanic cases are more likely than whites to have EBV-associated HL and that the mixed cellularity subtype is most commonly diagnosed in EBV-related malignancies. $(9,30-32)$ One pooled analysis found that the highest percentages of EBV-associated cases occurred among children $<10$ and in older adults, and that Hispanics were four times as likely as whites to have EBV-associated HL. (9) Another study comparing pediatric HL from Honduras and the US found that $100 \%$ and $57 \%$ of cases, respectively, were EBV-associated. (30) Our case population is among the largest to confirm the strong association between Hispanic ethnicity and HL risk for children 0-5 years of age. While we do not have data on EBV status, the high proportion of mixed-cellularity subtype among Hispanics supports the potential link between EBV and $\mathrm{HL}$ in our population. 
In our analyses of all lymphoma cases combined, we observed an increased risk for those with the birth complications tocolysis and fetopelvic disproportion, as well as reports of previous preterm birth, which is a factor associated with elevated risk for birth complications in subsequent pregnancies. Associations between tocolysis and previous preterm birth with lymphoma have not been reported elsewhere. Tocolytics are most commonly used to inhibit preterm labor, although use of tocolytics has also been suggested for management of fetal distress. (24) Fetal distress was not reported to differ among cases and controls, thus tocolysis most likely is an indicator of preterm labor. Many different agents are available for use as tocolytics, including beta-mimetics, magnesium sulfate, calcium channel blockers, prostaglandin inhibitors, and oxytocin receptor blockers.(33) These classes of drugs not only differ in mechanism of action, but also in contraindications and potential side effects. We do not have information on the type of tocolytic used and thus are unable to assess whether a particular agent is driving the association between tocolysis and lymphoma in our data. Previous preterm birth is a strong risk factor for subsequent preterm birth. (34) Additionally, the positive association between all types of lymphoma and previous stillbirth is similar to results from two previous studies of NHL. $(14,21)$ Women with previous stillbirth also are at higher risk for preterm birth in subsequent pregnancies. $(24,35,36)$ Despite the higher prevalence of these risk factors for preterm birth among cases, frequency of preterm births was similar in cases and controls. These associations may therefore point to tocolytic agents used to prevent or manage preterm labor or factors contributing to preterm labor.

Fetopelvic disproportion arises from diminished pelvic capacity, excessive fetal size, or a combination of both. (24) Although fetal size can contribute to fetopelvic disproportion, most cases of disproportion occur in a fetus within normal weight range. (24) In our population, the mean birth weight of cases and controls affected by fetopelvic disproportion was $3642 \mathrm{~g}$ and $4075 \mathrm{~g}$, respectively. Thus, birth weight does not account for the increase of fetopelvic disproportion among cases, and adjusting for birth weight did not remove the association between lymphoma and fetopelvic disproportion.

In stratified analyses, premature rupture of the membranes (PROM) was associated with NHL. PROM is associated with intra-amniotic infection, low socioeconomic status, low body mass index (<19.8), nutritional deficiencies, and cigarette smoking. (24) We also observed an association between meconium staining of the amniotic fluid and HL risk. Meconium staining is associated with fetal distress and fetal acidosis and may indicate fetal hypoxia. (24) These factors may not directly contribute to risk of lymphoma, instead acting as a proxy for other risk factors.

This study also identified an increased risk of miscellaneous and unspecified lymphomas among those with HBW and large size for gestational age. Many factors contribute to fetal growth, including genetic potential, maternal nutritional status, placental function, and intrauterine hormonal factors.(37) Previous studies have noted a relationship between HBW and pediatric leukemia that is particularly strong among young children ( $<2$ years). $(20,38)$ Our results may indicate a similar pattern given that most miscellaneous and unspecified lymphomas are diagnosed within the first year of life.(2) The underlying biological mechanisms in this association may be driven by growth factors such as the insulin-like 
growth factor (IGF) family, which impact both birth weight and carcinogenic cell proliferation. $(38,39)$

Our study is restricted to information provided on California birth certificates. Some variables were collected during a subset of study years, thereby further limiting our assessments. We conducted many tests of association and some of our results may be due to chance. Further research is needed to confirm positive results. Furthermore, due to limited sample sizes we were not able to stratify our results for some birth characteristics by lymphoma subtypes, thus we are not able to determine whether these associations are be specific to certain subtypes using these data. Birth certificate information has varying levels of validity. (40-44) One study reported a very high sensitivity (>94\%) for most race information on California birth certificates. (41) Additionally, birth weight and method of delivery tend to have the highest sensitivity and specificity. (42-44) Maternal factors also have good validity (40), whereas pregnancy complications generally have high (>95\%) specificity but low sensitivity (42-44).

Our study represents one of the largest population-based case-control studies of pediatric lymphoma. This study has strengths in that we have a large number of Hispanic mothers which allowed us to examine risk in these populations separately. Additionally, given the prospective nature of birth certificate data collection, we do not expect differential misclassification to have influenced our results. Our study population is likely to be free of selection bias due to non-participation because of records-based control sampling.

Our study confirms previous findings on Hispanic ethnicity and lymphomas and also reports novel associations. While we found associations between pediatric lymphoma and several birth certificate variables, many of these may be markers of other factors that contribute to lymphoma development. Future research should include studies large enough to distinguish cases not only according to lymphoma type but also by age of onset, since lymphomas occurring early in life may have different etiologies than those occurring in older children $(1,45)$. Our findings corroborate the EBV hypothesis for $\mathrm{HL}$ and also suggest that other factors, such as intra-uterine infections and factors associated with preterm labor may be involved in lymphoma pathogenesis.

\section{Supplementary Material}

Refer to Web version on PubMed Central for supplementary material.

\section{Acknowledgments}

This study was supported by grants from the National Institute of Environmental Health Sciences (R21ES018960, R21ES019986, P30ES007048). Dr. Erin Marcotte was supported by a pre-doctoral fellowship from the National Institutes of Health, National Cancer Institute T32 CA09142.

Role of the Funding Source: The funders had no role in study design, data collection and analysis, decision to publish, or preparation of the manuscript. 


\section{References}

1. Constance, L.; Percy, MAS.; Martha, Linet; Lynn, A.; Gloeckler, Ries; Friedman, Debra L. SEER Pediatric Monograph: Lymphomas and Reticuloendothelial Neoplasms. Ries, LAG.; S, M.; Gurney, JG.; Linet, M.; Tamra, T.; Young, JL.; Bunin, GR., editors. Bethesda, MD: National Cancer Institute: SEER Program; 1999.

2. Howlader, NNA.; Krapcho, M.; Neyman, N.; Aminou, R.; Waldron, W.; Altekruse, SF.; Kosary, CL.; Ruhl, J.; Tatalovich, Z.; Cho, H.; Mariotto, A.; Eisner, MP.; Lewis, DR.; Chen, HS.; Feuer, EJ.; Cronin, KA.; Edwards, BK., editors. SEER Cancer Statistics Review, 1975-2008. Bethesda, MD: National Cancer Institute; 2011.

3. Chapin RE, Robbins WA, Schieve LA, Sweeney AM, Tabacova SA, Tomashek KM. Off to a good start: the influence of pre- and periconceptional exposures, parental fertility, and nutrition on children's health. Environ Health Perspect. 2004; 112(1):69-78. Epub 2003/12/31. [PubMed: 14698934]

4. Selevan SG, Kimmel CA, Mendola P. Identifying critical windows of exposure for children's health. Environ Health Perspect. 2000; 108 Suppl 3:451-5. Epub 2000/06/15. [PubMed: 10852844]

5. Anderson LM, Diwan BA, Fear NT, Roman E. Critical windows of exposure for children's health: cancer in human epidemiological studies and neoplasms in experimental animal models. Environ Health Perspect. 2000; 108 Suppl 3:573-94. Epub 2000/06/15. [PubMed: 10852857]

6. Antonopoulos C, Sergentanis T, Papadopoulou C, Andrie E, Dessypris N, Panagopoulou P, et al. Maternal smoking during pregnancy and childhood lymphoma: A meta-analysis. Int J Cancer. 2011 Epub 2011/01/13.

7. Gaini RM, Romagnoli M, Sala A, Garavello W. Lymphomas of head and neck in pediatric patients. Int J Pediatr Otorhinolaryngol. 2009; 73 Suppl 1:S65-70. Epub 2010/02/02. [PubMed: 20114159]

8. Thorley-Lawson DA, Gross A. Persistence of the Epstein-Barr virus and the origins of associated lymphomas. N Engl J Med. 2004; 350(13):1328-37. Epub 2004/03/27. [PubMed: 15044644]

9. Glaser SL, Lin RJ, Stewart SL, Ambinder RF, Jarrett RF, Brousset P, et al. Epstein-Barr virusassociated Hodgkin's disease: epidemiologic characteristics in international data. Int J Cancer. 1997; 70(4):375-82. Epub 1997/02/07. [PubMed: 9033642]

10. Non-Hodgkin Lymphoma in Children. Atlanta, GA: American Cancer Society; 2011.

11. Kersey JH, Shapiro RS, Filipovich AH. Relationship of immunodeficiency to lymphoid malignancy. Pediatr Infect Dis J. 1988; 7(5 Suppl):S10-2. Epub 1988/05/01. [PubMed: 2840629]

12. McClain KL, Joshi VV, Murphy SB. Cancers in children with HIV infection. Hematol Oncol Clin North Am. 1996; 10(5):1189-201. Epub 1996/10/01. [PubMed: 8880205]

13. Schuz J, Kaatsch P, Kaletsch U, Meinert R, Michaelis J. Association of childhood cancer with factors related to pregnancy and birth. Int J Epidemiol. 1999; 28(4):631-9. Epub 1999/09/10. [PubMed: 10480689]

14. Roman E, Simpson J, Ansell P, Lightfoot T, Mitchell C, Eden TO. Perinatal and reproductive factors: a report on haematological malignancies from the UKCCS. Eur J Cancer. 2005; 41(5): 749-59. Epub 2005/03/15. [PubMed: 15763652]

15. Wong DI, Dockerty JD. Birth characteristics and the risk of childhood leukaemias and lymphomas in New Zealand: a case-control study. BMC Blood Disord. 2006; 6:5. Epub 2006/09/16. [PubMed: 16972984]

16. Yip BH, Pawitan Y, Czene K. Parental age and risk of childhood cancers: a population-based cohort study from Sweden. Int J Epidemiol. 2006; 35(6):1495-503. Epub 2006/09/30. [PubMed: 17008361]

17. McKinney PA, Juszczak E, Findlay E, Smith K, Thomson CS. Pre- and perinatal risk factors for childhood leukaemia and other malignancies: a Scottish case control study. Br J Cancer. 1999; 80(11):1844-51. Epub 1999/09/01. [PubMed: 10468308]

18. Rangel M, Cypriano M, de Martino Lee ML, Luisi FA, Petrilli AS, Strufaldi MW, et al. Leukemia, non-Hodgkin's lymphoma, and Wilms tumor in childhood: the role of birth weight. Eur J Pediatr. 2010; 169(7):875-81. Epub 2010/01/27. [PubMed: 20101509] 
19. Smith A, Lightfoot T, Simpson J, Roman E. Birth weight, sex and childhood cancer: A report from the United Kingdom Childhood Cancer Study. Cancer Epidemiol. 2009; 33(5):363-7. Epub 2009/11/26. [PubMed: 19932649]

20. Yeazel MW, Ross JA, Buckley JD, Woods WG, Ruccione K, Robison LL. High birth weight and risk of specific childhood cancers: a report from the Children's Cancer Group. J Pediatr. 1997; 131(5):671-7. Epub 1997/12/24. [PubMed: 9403644]

21. Adami J, Glimelius B, Cnattingius S, Ekbom A, Zahm SH, Linet M, et al. Maternal and perinatal factors associated with non-Hodgkin's lymphoma among children. Int J Cancer. 1996; 65(6):7747. Epub 1996/03/15. [PubMed: 8631590]

22. Steliarova-Foucher E, Stiller C, Lacour B, Kaatsch P. International Classification of Childhood Cancer, third edition. Cancer. 2005; 103(7):1457-67. Epub 2005/02/16. [PubMed: 15712273]

23. Heck JE, Lombardi CA, Meyers TJ, Cockburn M, Wilhelm M, Ritz B. Perinatal characteristics and retinoblastoma. Cancer Causes Control. 2012; 23(9):1567-75. Epub 2012/07/31. [PubMed: 22843021]

24. Cunningham, FG.; Williams, JW. Williams obstetrics. 23rd. New York: McGraw-Hill Medical; 2010. p. xvp. 1385

25. Alexander GR, Himes JH, Kaufman RB, Mor J, Kogan M. A United States national reference for fetal growth. Obstet Gynecol. 1996; 87(2):163-8. Epub 1996/02/01. [PubMed: 8559516]

26. Ritz B, Wilhelm M, Hoggatt KJ, Ghosh JK. Ambient air pollution and preterm birth in the environment and pregnancy outcomes study at the University of California, Los Angeles. Am J Epidemiol. 2007; 166(9):1045-52. Epub 2007/08/07. [PubMed: 17675655]

27. Roman E, Ansell P, Bull D. Leukaemia and non-Hodgkin's lymphoma in children and young adults: are prenatal and neonatal factors important determinants of disease? Br J Cancer. 1997; 76(3):406-15. Epub 1997/01/01. [PubMed: 9252212]

28. Chow EJ, Puumala SE, Mueller BA, Carozza SE, Fox EE, Horel S, et al. Childhood cancer in relation to parental race and ethnicity: a 5-state pooled analysis. Cancer. 2010; 116(12):3045-53 Epub 2010/06/22. [PubMed: 20564410]

29. Fast Stats: An interactive tool for access to SEER cancer statistics. Surveillance Research Program, National Cancer Institute. cited 2012 2-10-12; Available from: http://seer.cancer.gov/faststats.

30. Ambinder RF, Browning PJ, Lorenzana I, Leventhal BG, Cosenza H, Mann RB, et al. Epstein-Barr virus and childhood Hodgkin's disease in Honduras and the United States. Blood. 1993; 81(2): 462-7. Epub 1993/01/15. [PubMed: 8380725]

31. Gulley ML, Eagan PA, Quintanilla-Martinez L, Picado AL, Smir BN, Childs C, et al. Epstein-Barr virus DNA is abundant and monoclonal in the Reed-Sternberg cells of Hodgkin's disease: association with mixed cellularity subtype and Hispanic American ethnicity. Blood. 1994; 83(6): 1595-602. Epub 1994/03/15. [PubMed: 8123850]

32. Glaser SL, Gulley ML, Clarke CA, Keegan TH, Chang ET, Shema SJ, et al. Racial/ethnic variation in EBV-positive classical Hodgkin lymphoma in California populations. Int J Cancer. 2008; 123(7):1499-507. Epub 2008/07/23. [PubMed: 18646185]

33. Haas DM, Caldwell DM, Kirkpatrick P, McIntosh JJ, Welton NJ. Tocolytic therapy for preterm delivery: systematic review and network meta-analysis. BMJ. 2012; 345:e6226. Epub 2012/10/11. [PubMed: 23048010]

34. Bloom SL, Yost NP, McIntire DD, Leveno KJ. Recurrence of preterm birth in singleton and twin pregnancies. Obstet Gynecol. 2001; 98(3):379-85. Epub 2001/09/01. [PubMed: 11530116]

35. Goldenberg RL, Mayberry SK, Copper RL, Dubard MB, Hauth JC. Pregnancy outcome following a second-trimester loss. Obstet Gynecol. 1993; 81(3):444-6. Epub 1993/03/01. [PubMed: 8437803]

36. Edlow AG, Srinivas SK, Elovitz MA. Second-trimester loss and subsequent pregnancy outcomes: What is the real risk? Am J Obstet Gynecol. 2007; 197(6):581 e1-6. Epub 2007/12/07. [PubMed: 18060941]

37. Gibney, M.; Margetts, B.; Kearney, J.; Arab, L., editors. Public Health Nutrition. Oxford, UK: Blackwell Science; 2004. 
38. Ross JA, Perentesis JP, Robison LL, Davies SM. Big babies and infant leukemia: a role for insulinlike growth factor-1? Cancer Causes Control. 1996; 7(5):553-9. Epub 1996/09/01. [PubMed: 8877054]

39. Estrov Z, Meir R, Barak Y, Zaizov R, Zadik Z. Human growth hormone and insulin-like growth factor-1 enhance the proliferation of human leukemic blasts. J Clin Oncol. 1991; 9(3):394-9. Epub 1991/03/01. [PubMed: 1999709]

40. Hosler AS, Nayak SG, Radigan AM. Agreement between self-report and birth certificate for gestational diabetes mellitus: New York State PRAMS. Matern Child Health J. 2009; 14(5):786-9. Epub 2009/10/20. [PubMed: 19838778]

41. Baumeister L, Marchi K, Pearl M, Williams R, Braveman P. The validity of information on "race" and "Hispanic ethnicity" in California birth certificate data. Health Serv Res. 2000; 35(4):869-83. Epub 2000/10/31. [PubMed: 11055453]

42. Roohan PJ, Josberger RE, Acar J, Dabir P, Feder HM, Gagliano PJ. Validation of birth certificate data in New York State. J Community Health. 2003; 28(5):335-46. Epub 2003/10/11. [PubMed: 14535599]

43. Reichman NE, Hade EM. Validation of birth certificate data. A study of women in New Jersey's HealthStart program. Ann Epidemiol. 2001; 11(3):186-93. Epub 2001/03/15. [PubMed: 11248582]

44. Northam S, Knapp TR. The reliability and validity of birth certificates. J Obstet Gynecol Neonatal Nurs. 2006; 35(1):3-12. Epub 2006/02/10.

45. Armstrong AA, Alexander FE, Cartwright R, Angus B, Krajewski AS, Wright DH, et al. EpsteinBarr virus and Hodgkin's disease: further evidence for the three disease hypothesis. Leukemia : official journal of the Leukemia Society of America, Leukemia Research Fund, UK. 1998; 12(8): 1272-6. Epub 1998/08/11. 

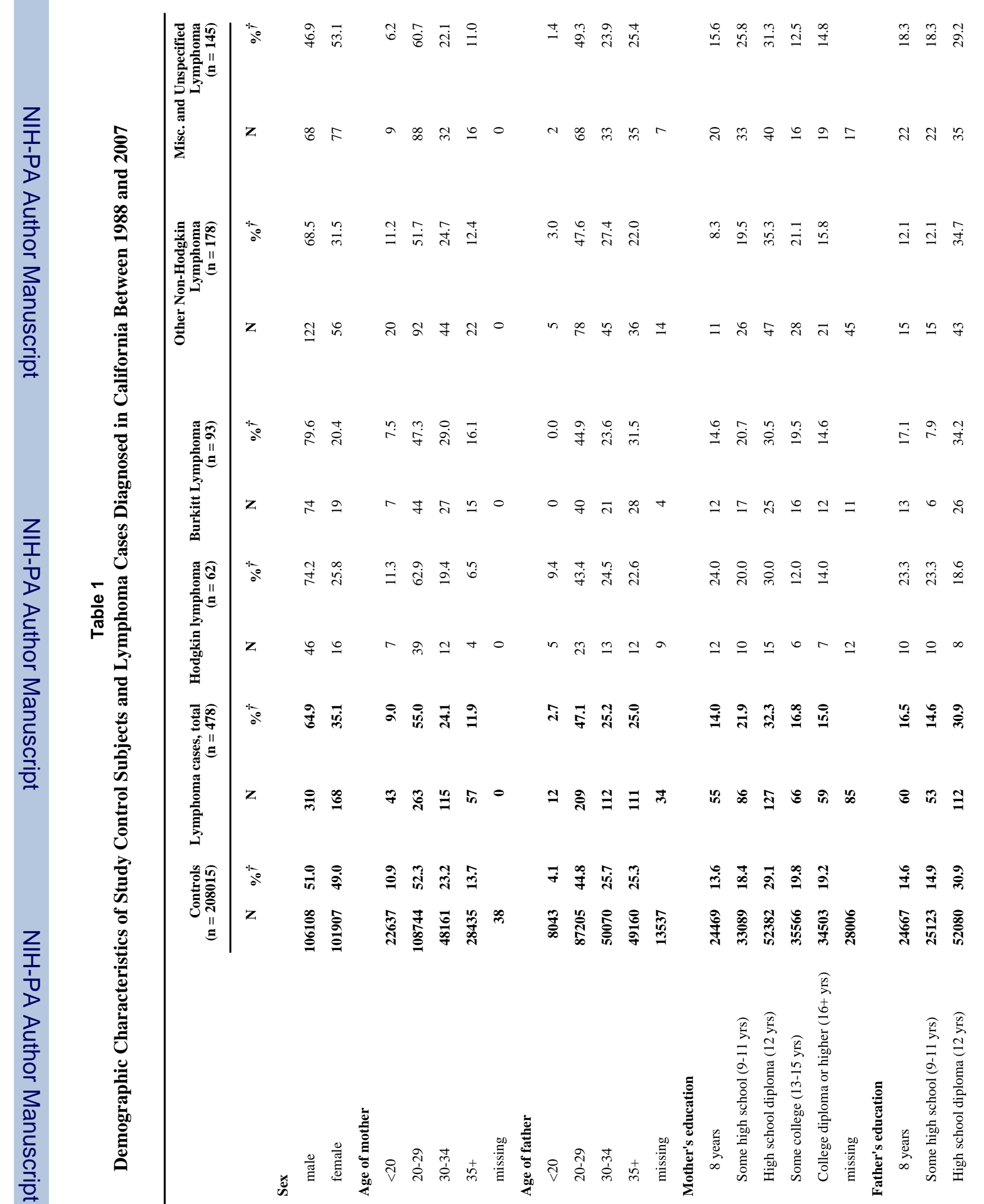


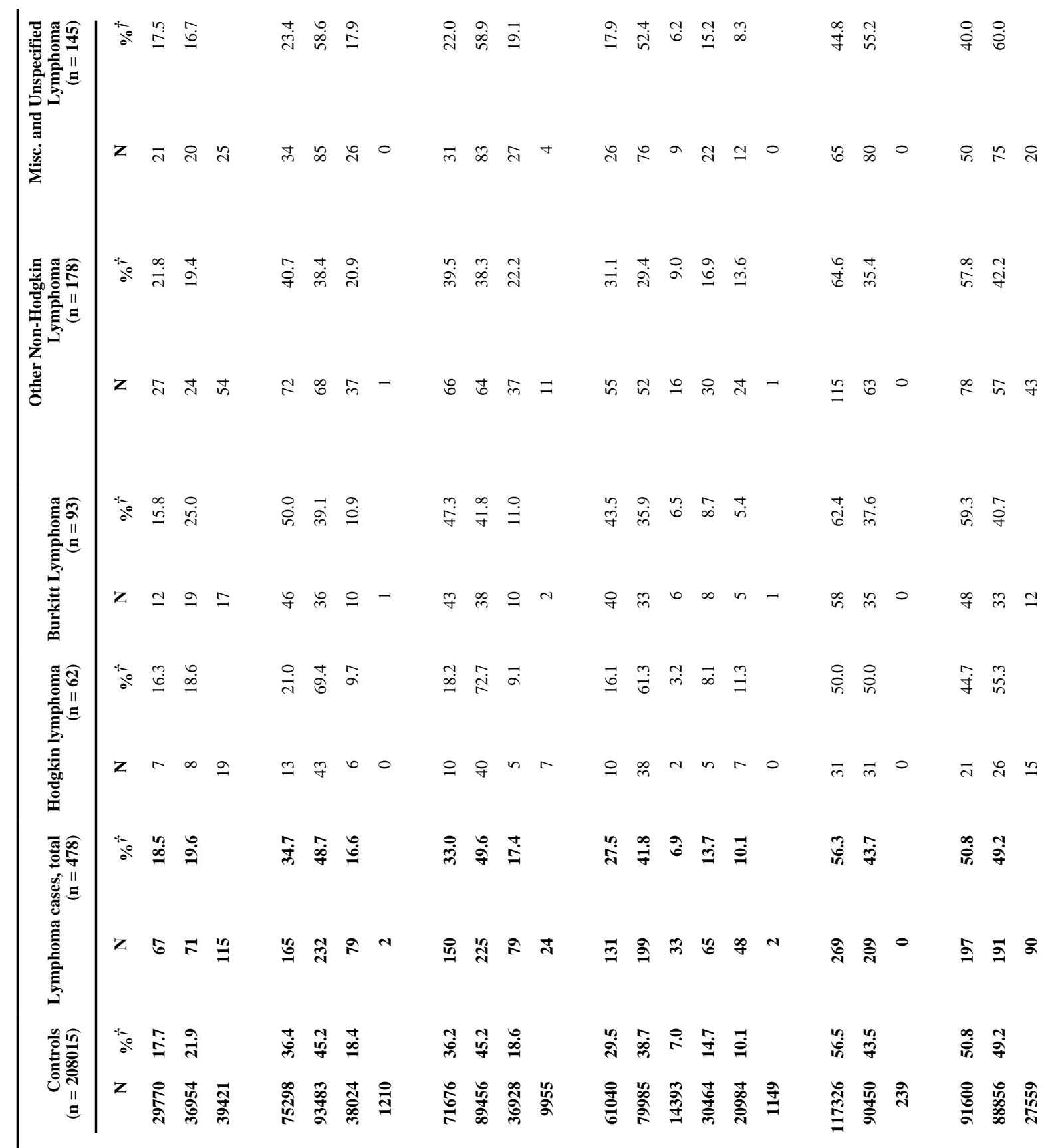

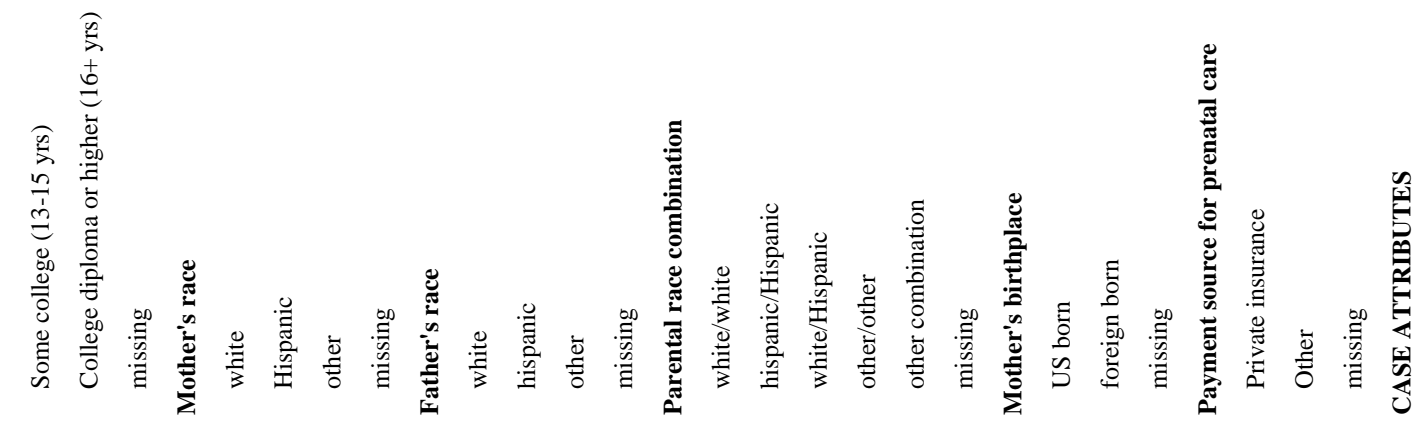




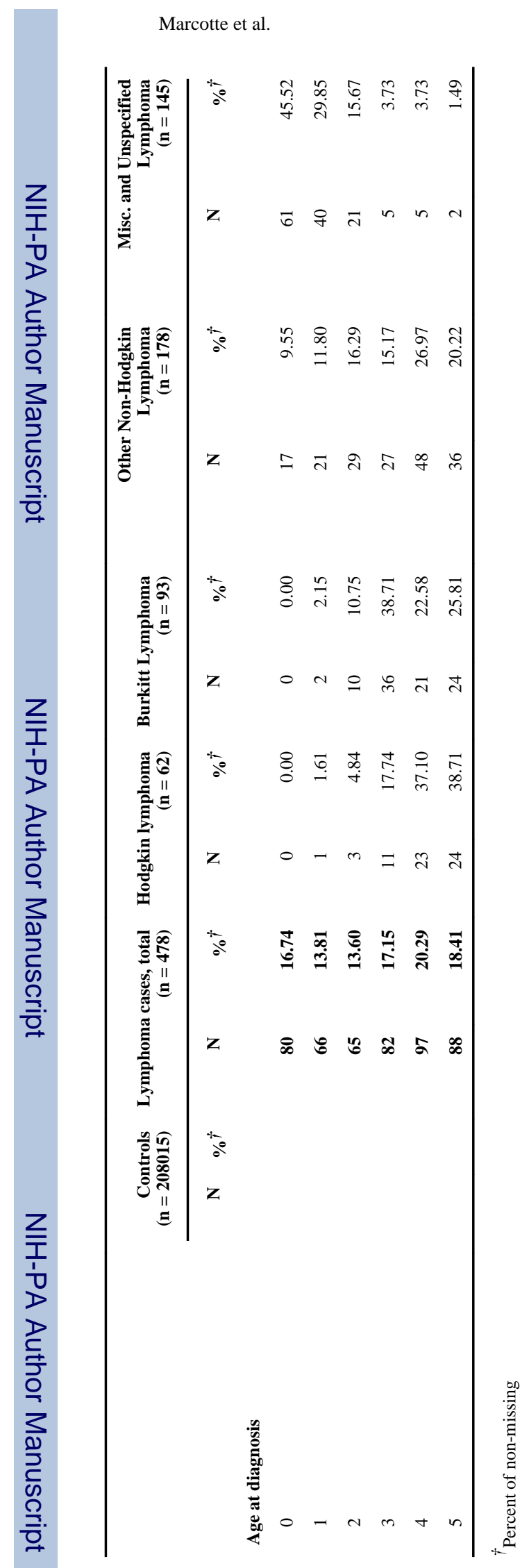

Cancer Epidemiol. Author manuscript; available in PMC 2015 February 01. 


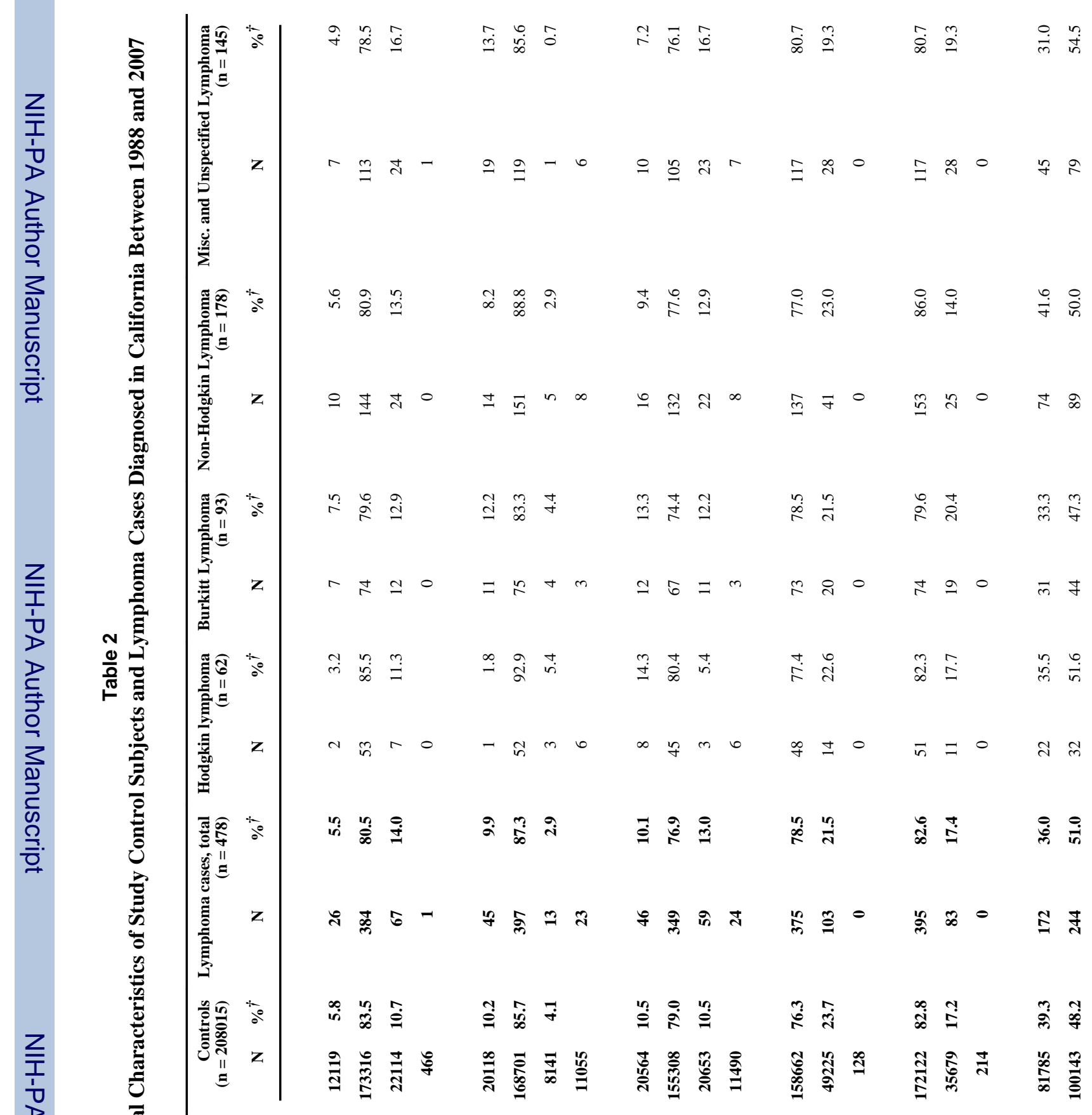


Table 3

Multivariate Analysis of Select Birth Certificate Variables in Relation to Lymphoma Risk Among California Children Age 0-5 Diagnosed Between 1988 and 2007

\begin{tabular}{|c|c|c|c|}
\hline & $\begin{array}{l}\text { Any Lymphoma } \mathrm{OR}^{\ddagger}(95 \% \\
\text { CI) }\end{array}$ & $\begin{array}{l}\text { Hodgkin Lymphoma OR } \\
\text { (95\% CI) }\end{array}$ & $\begin{array}{l}\text { Non-Hodgkin Lymphoma } \\
\text { OR }^{\ddagger}(95 \% \text { CI) }\end{array}$ \\
\hline \multicolumn{4}{|l|}{ Sex } \\
\hline male & $1.81(1.47,2.23)$ & $2.81(1.46,5.42)$ & $2.58(1.91,3.49)$ \\
\hline female & ref & ref & ref \\
\hline \multicolumn{4}{|l|}{ Birth weight, $g$} \\
\hline$<2500$ & $0.89(0.56,1.41)$ & - & $1.09(0.62,1.92)$ \\
\hline 2500-3999 & ref & ref & ref \\
\hline $4000+$ & $1.23(0.91,1.67)$ & $1.02(0.40,2.77)$ & $1.03(0.67,1.59)$ \\
\hline \multicolumn{4}{|l|}{ Gestational age, weeks } \\
\hline$\leq 36$ & $0.87(0.60,1.24)$ & - & $0.81(0.49,1.34)$ \\
\hline $37-42$ & ref & ref & ref \\
\hline $43+$ & $0.59(0.31,1.15)$ & $0.96(0.23,3.97)$ & $0.70(0.31,1.59)$ \\
\hline \multicolumn{4}{|l|}{ Size for gestational age } \\
\hline Small & $1.06(0.76,1.48)$ & $1.53(0.68,3.45)$ & $1.13(0.74,1.73)$ \\
\hline Normal & ref & ref & ref \\
\hline Large & $1.18(0.85,1.63)$ & $0.50(0.12,2.06)$ & $0.98(0.62,1.56)$ \\
\hline \multicolumn{4}{|l|}{ Age of mother ${ }^{*}$} \\
\hline$<20$ & $0.80(0.56,1.14)$ & $0.94(0.39,2.29)$ & $1.05(0.66,1.66)$ \\
\hline $20-29$ & ref & ref & ref \\
\hline $30-34$ & $0.98(0.77,1.26)$ & $1.08(0.54,2.15)$ & $1.07(0.77,1.49)$ \\
\hline $35+$ & $0.79(0.57,1.10)$ & $0.16(0.02,1.18)$ & $0.88(0.58,1.35)$ \\
\hline \multicolumn{4}{|l|}{ Age of father } \\
\hline$<20$ & $0.49(0.24,1.00)$ & $0.91(0.20,4.16)$ & $0.49(0.18,1.37)$ \\
\hline $20-29$ & ref & ref & ref \\
\hline $30-34$ & $0.95(0.72,1.27)$ & $1.65(0.70,3.90)$ & $0.82(0.56,1.20)$ \\
\hline $35+$ & $0.92(0.66,1.30)$ & $1.81(0.64,5.12)$ & $0.71(0.45,1.13)$ \\
\hline \multicolumn{4}{|l|}{ Mother's education } \\
\hline$\leq 8$ years & $0.87(0.61,1.24)$ & $1.08(0.46,2.54)$ & $0.75(0.44,1.28)$ \\
\hline Some high school (9-11 yrs) & $1.11(0.83,1.48)$ & $0.74(0.32,1.75)$ & $1.16(0.77,1.73)$ \\
\hline High school diploma (12 yrs) & ref & ref & ref \\
\hline Some college (13-15 yrs) & $0.77(0.57,1.04)$ & $0.72(0.27,1.88)$ & $0.82(0.56,1.21)$ \\
\hline College diploma or higher (16+yrs) & $0.70(0.50,0.98)$ & $1.22(0.45,3.32)$ & $0.58(0.37,0.91)$ \\
\hline \multicolumn{4}{|l|}{ Father's education } \\
\hline$\leq 8$ years & $1.08(0.76,1.52)$ & $1.80(0.66,4.93)$ & $0.99(0.60,1.62)$ \\
\hline Some high school (9-11 yrs) & $0.95(0.67,1.34)$ & $1.88(0.70,5.00)$ & $0.76(0.46,1.26)$ \\
\hline High school diploma (12 yrs) & ref & ref & ref \\
\hline Some college (13-15 yrs) & $1.09(0.80,1.49)$ & $1.83(0.65,5.12)$ & $0.94(0.63,1.41)$ \\
\hline College diploma or higher (16+yrs) & $0.95(0.68,1.32)$ & $2.22(0.76,6.49)$ & $0.79(0.52,1.20)$ \\
\hline
\end{tabular}




\begin{tabular}{|c|c|c|c|}
\hline & $\begin{array}{l}\text { Any Lymphoma } \mathrm{OR}^{\ddagger}(95 \% \\
\text { CI) }\end{array}$ & $\begin{array}{l}\text { Hodgkin Lymphoma OR } \\
\text { (95\% CI) }\end{array}$ & $\begin{array}{l}\text { Non-Hodgkin Lymphoma } \\
\text { OR }{ }^{\dagger}(95 \% \text { CI })\end{array}$ \\
\hline \multicolumn{4}{|l|}{ Mother's race ${ }^{*}$} \\
\hline white & ref & ref & ref \\
\hline hispanic & $1.14(0.90,1.45)$ & $2.43(1.14,5.17)$ & $0.80(0.58,1.10)$ \\
\hline other & $0.94(0.69,1.27)$ & $1.21(0.44,3.35)$ & $0.74(0.50,1.11)$ \\
\hline \multicolumn{4}{|l|}{ Father's race } \\
\hline white & ref & ref & ref \\
\hline Hispanic & $1.42(0.98,2.06)$ & $1.60(0.50,5.13)$ & $1.26(0.78,2.04)$ \\
\hline other & $1.03(0.64,1.65)$ & $0.98(0.19,5.02)$ & $0.85(0.46,1.59)$ \\
\hline \multicolumn{4}{|l|}{ Parental race combination } \\
\hline white/white & ref & ref & ref \\
\hline hispanic/hispanic & $1.19(0.91,1.56)$ & $2.23(0.99,5.01)$ & $0.81(0.57,1.15)$ \\
\hline white/hispanic & $1.02(0.67,1.58)$ & - & $1.02(0.61,1.72)$ \\
\hline other/other & $0.97(0.69,1.36)$ & $1.13(0.38,3.39)$ & $0.76(0.48,1.18)$ \\
\hline \multicolumn{4}{|l|}{ Mother's birthplace } \\
\hline US born & ref & ref & ref \\
\hline foreign born & $0.88(0.69,1.11)$ & $0.77(0.40,1.47)$ & $0.85(0.61,1.19)$ \\
\hline \multicolumn{4}{|l|}{ Method of delivery } \\
\hline Vaginal & ref & ref & ref \\
\hline Caesarean & $0.97(0.76,1.23)$ & $1.39(0.73,2.65)$ & $1.01(0.74,1.39)$ \\
\hline \multicolumn{4}{|l|}{ Previous terminations } \\
\hline None & ref & ref & ref \\
\hline $1+$ & $1.11(0.85,1.44)$ & $1.16(0.54,2.52)$ & $0.93(0.64,1.34)$ \\
\hline \multicolumn{4}{|l|}{ Parity } \\
\hline first birth & ref & ref & ref \\
\hline second or third birth & $1.13(0.90,1.42)$ & $1.23(0.65,2.34)$ & $0.98(0.73,1.32)$ \\
\hline fourth or subsequent birth & $1.04(0.72,1.50)$ & $0.79(0.24,2.56)$ & $0.97(0.59,1.59)$ \\
\hline \multicolumn{4}{|l|}{ Prenatal care initiation } \\
\hline During first trimester & ref & ref & ref \\
\hline No care or after first trimester & $1.19(0.92,1.53)$ & $0.90(0.43,1.85)$ & $1.07(0.75,1.54)$ \\
\hline \multicolumn{4}{|l|}{ Payment source for prenatal care } \\
\hline Private insurance & ref & ref & ref \\
\hline Other & $0.95(0.76,1.18)$ & $0.86(0.46,1.60)$ & $0.78(0.58,1.05)$ \\
\hline
\end{tabular}

FORs are adjusted for birth year, maternal age and race, and prenatal payment source

* Maternal age analyses are adjusted for birth year, maternal race, and prenatal payment source. Maternal race analyses are adjusted for birth year, maternal age, and prenatal payment source 
Table 4

Multivariate Analysis of Pregnancy and Labor/Delivery Complications in Relation to Lymphoma Risk Among California Children Age 0-5 Diagnosed Between 1988 and 2007

\begin{tabular}{|c|c|c|c|}
\hline & Controls & Lymphoma cases, total & \\
\hline & $\mathrm{N} / \mathrm{N}$ total ${ }^{*}$ & N/ N total* & $\mathrm{OR}^{\dagger}(95 \% \mathrm{CI})$ \\
\hline \multicolumn{4}{|l|}{ Years collected 2006+ } \\
\hline Epidural & $2980 / 7780$ & $6 / 14$ & $0.85(0.27,2.68)$ \\
\hline \multicolumn{4}{|l|}{ 1989-2005 } \\
\hline Premature labor & $4169 / 174962$ & $10 / 384$ & $1.15(0.62,2.17)$ \\
\hline Amniocentisis & $4158 / 174962$ & $6 / 384$ & $0.68(0.30,1.53)$ \\
\hline Tocolysis & $1536 / 174962$ & $7 / 384$ & $2.24(1.06,4.75)$ \\
\hline Febrile (> 100 F) & $2052 / 174962$ & $6 / 384$ & $1.40(0.62,3.14)$ \\
\hline \multicolumn{4}{|l|}{ 1989+ } \\
\hline Previous pre-term birth & $2013 / 182742$ & $9 / 398$ & $2.22(1.14,4.32)$ \\
\hline Pre-eclampsia & $3897 / 182742$ & $6 / 398$ & $0.73(0.33,1.63)$ \\
\hline Prolonged labor ( $>20$ hours) & $1380 / 182742$ & $5 / 398$ & $1.73(0.71,4.18)$ \\
\hline Premature rupture of membrane & $3505 / 182742$ & $10 / 398$ & $1.38(0.73,2.58)$ \\
\hline Induction of labor & $16921 / 182742$ & $29 / 398$ & $0.80(0.56,1.18)$ \\
\hline Stimulation of labor & $18144 / 182742$ & $38 / 398$ & $0.97(0.69,1.36)$ \\
\hline Moderate/heavy meconium staining of amniotic fluid & $7629 / 182742$ & $22 / 398$ & $1.39(0.90,2.13)$ \\
\hline \multicolumn{4}{|l|}{ All study years } \\
\hline Small for gestational age & $20564 / 196525$ & $46 / 454$ & $1.04(0.75,1.45)$ \\
\hline Large for gestational age & $20653 / 196525$ & $59 / 454$ & $1.17(0.85,1.62)$ \\
\hline Preterm birth & $20118 / 196960$ & $45 / 455$ & $0.88(0.62,1.26)$ \\
\hline \multicolumn{4}{|l|}{ 1986-2005 } \\
\hline Fetopelvic disproportion & $4803 / 200235$ & $17 / 464$ & $1.93(1.15,3.24)$ \\
\hline Breech or other abnormal presentation & $5944 / 200235$ & $12 / 464$ & $0.73(0.36,1.47)$ \\
\hline Fetal distress & $6308 / 200235$ & $12 / 464$ & $0.86(0.46,1.62)$ \\
\hline \multicolumn{4}{|l|}{ All study years } \\
\hline Low birth weight & $12119 / 207549$ & $26 / 477$ & $0.87(0.55,1.37) 1.37)$ \\
\hline High birth weight & $22114 / 207549$ & $67 / 477$ & $1.24(0.92,1.68)$ \\
\hline Previous still birth & $3008 / 207687$ & $9 / 478$ & $1.31(0.62,2.78)$ \\
\hline
\end{tabular}




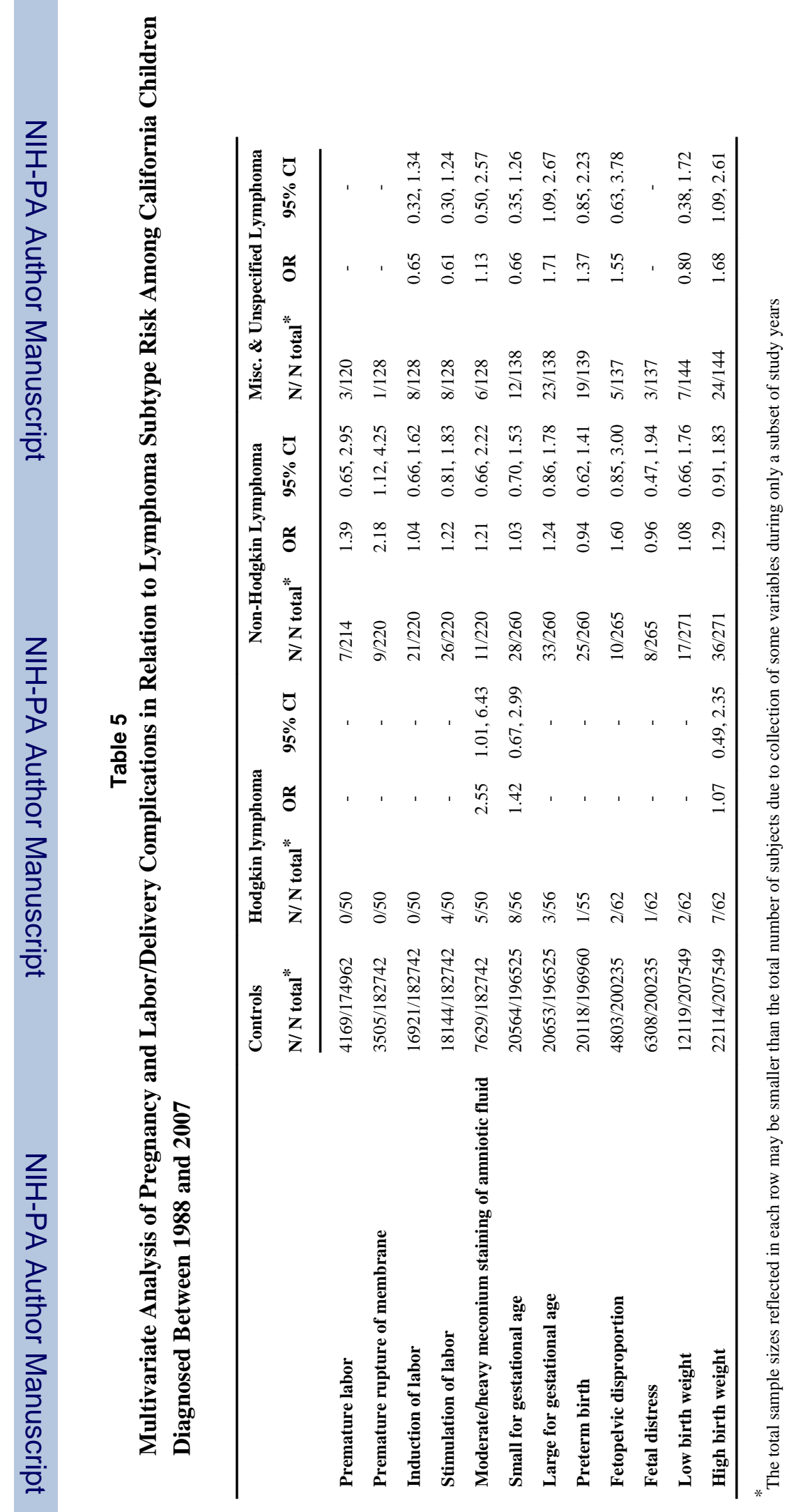

Cancer Epidemiol. Author manuscript; available in PMC 2015 February 01. 